\title{
Anesthesia management in a case of Von Recklinghausen neurofibromatosis
}

\author{
Nishith Govil and Vijay Adabala \\ Department of Anesthesiology, All India Institute of Medical Sciences, Rishikesh, India
}

Anesthetic considerations in cases of von Recklinghausen neurofibromatosis differ with varying severity of systemic involvement [1]. After taking written consent of the patient for possible publication of her case in medical literature, we are reporting case of Von Recklinghausen neurofibromatosis in a 55-year-old female, operated for hysterectomy for dysfunctional uterine bleeding, having extensive nodular neurofibroma all over the body (Fig. 1A). Systemic examination revealed normal airway, moderate restrictive lung disease, moderate hypertension, and normal screening magnetic resonance imaging of the brain and spine.

General anesthesia was administered as per standard proto- col except for reduced doses of non-depolarizing neuromuscular blocking agent (NdNMBA) along with neuromuscular monitoring (Fig. 1B). Intraoral airway was normal and neck extension was minimized to prevent the cervical spine injury during laryngoscopy. Peri-operative period remained uneventful except for increased sensitivity to vecuronium and residual muscle paralysis in post-anesthesia care unit (PACU) even after administering required doses of neostigmine for reversal of NMBA. In the PACU, the patient had to be supported with invasive ventilation for maintaining adequate minute ventilation for two hours without any further complications.

Neurofibromatosis is an autosomal dominant disease of the
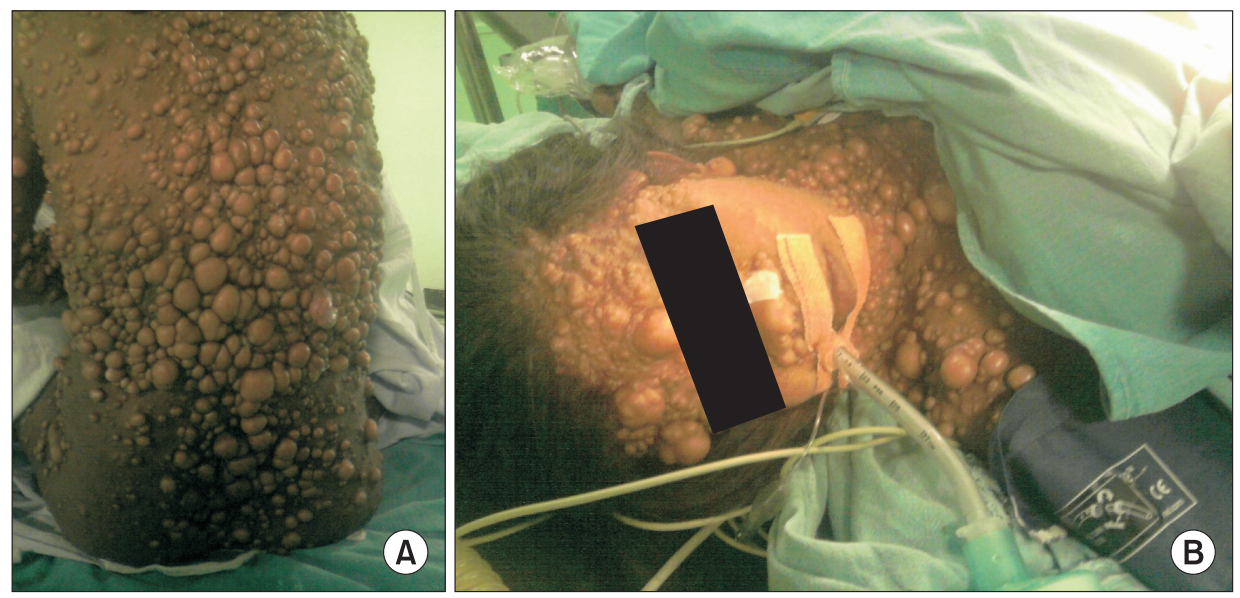

Fig. 1. (A) Patient with extensive nodular neurofibroma all over the body. (B) Increased sensitivity to non-depolarizing neuromuscular blocking agent (NdNMBA).

\footnotetext{
Corresponding author: Nishith Govil, M.D.

Department of Anesthesiology, All India Institute of Medical Sciences, Rishikesh-Pin 249203, Uttaranchal, India Tel: 91-8126101759, Fax: 91-0135-2752946, Email: nishithgovil@rediffmail.com

ORCID: https://orcid.org/0000-0003-3749-6217
}

Received: August 29, 2018. Revised: August 30, 2018. Accepted: September 12, 2018.

Korean J Anesthesiol 2019 April 72(2): 194-195

https://doi.org/10.4097/kja.d.18.00251

(c) This is an open-access article distributed under the terms of the Creative Commons Attribution Non-Commercial License (http://creativecommons.org/ licenses/by-nc/4.0/), which permits unrestricted non-commercial use, distribution, and reproduction in any medium, provided the original work is properly cited. 
ectodermal and mesodermal tissue with varying incidence and severity of involvement of all organ systems. General anesthesia is preferred over regional anesthesia owing to a number of reasons, but if intraoral pathology is suspected, regional techniques should be adopted. Richardson et al. [2] recommended no reduction in doses of NdNMBA after a retrospective review of data of anesthetized Von Recklinghausen neurofibromatosis patients. Nevertheless, keeping the patient euthermic by active heating and use of neuromuscular monitoring is a prudent approach to avoid residual muscle paralysis [1]. However, rarely encountered, Von Recklinghausen neurofibromatosis poses a fundamental challenge in the decision making of the perioperative care provider for improved outcome of the patient.

\section{Conflicts of Interest}

No potential conflict of interest relevant to this article was reported.

\section{Author Contributions}

Nishith Govil (Writing - original draft)

Vijay Adabala (Conceptualization)

\section{ORCID}

Nishith Govil, https://orcid.org/0000-0003-3749-6217

Vijay Adabala, https://orcid.org/0000-0002-5969-8947

\section{References}

1. Hirsch NP, Murphy A, Radcliffe JJ. Neurofibromatosis: clinical presentations and anaesthetic implications. Br J Anaesth 2001; 86: 555-64.

2. Richardson MG, Setty GK, Rawoof SA. Responses to nondepolarizing neuromuscular blockers and succinylcholine in von Recklinghausen neurofibromatosis. Anesth Analg 1996; 82: 382-5. 